2003;95(12):868-878

3. Schröder FH, et al. Screening and prostate-cancer mortality in a randomized european study. $N$ EnglJ Med. 2009;360(13):1320-1328.

4. Hugosson J, et al. Mortality results from the Göteborg randomised population-based prostate-cancer screening trial. Lancet Oncol. 2010;11(8):725-732.

5. Stattin P, et al. Outcomes in localized prostate cancer: National Prostate Cancer Register of Sweden follow-up study. J Natl Cancer Inst. 2010; 102(13):950-958

6. Tosoian JJ, et al. Active surveillance program for prostate cancer: an update of the Johns Hopkins experience. J Clin Oncol. 2011;29(16):2185-2190.

7. Rinn JL, Chang HY. Genome regulation by long noncoding RNAs. Annu Rev Biochem. 2012;81:145-166.

8. Glinsky GV. Phenotype-defining functions of multiple non-coding RNA pathways. Cell Cycle. 2008;7(11):1630-1639

9. Lee JT. Epigenetic regulation by long noncoding RNAs. Science. 2012;338(6113):1435-1439.

10. Wang KC, Chang HY. Molecular mechanisms of long noncoding RNAs. Mol Cell. 2011;43(6):904-914.

11. Glinskii $A B$, et al. Identification of intergenic trans-regulatory RNAs containing a disease-linked SNP sequence and targeting cell cycle progression/ differentiation pathways in multiple common human disorders. Cell Cycle. 2009;8(23):3925-3942.

12. Martin L, Chang HY. Uncovering the role of genomic "dark matter" in human disease. J Clin
Invest. 2012;122(5):1589-1595.

13. Glinskii $A B$, et al. Networks of intergenic longrange enhancers and snpRNAs drive castrationresistant phenotype of prostate cancer and contribute to pathogenesis of multiple common human disorders. Cell Cycle. 2011;10(20):3571-3597.

14. Lightfoot HL, Hall J. Target mRNA inhibition by oligonucleotide drugs in man. Nucleic Acids Res. 2012;40(21):10585-10595.

15. Olsen AL, Davies JM, Medley L, Breen D, Talbot DC, McHugh PJ. Quantitative analysis of survivin protein expression and its therapeutic depletion by an antisense oligonucleotide in human lung tumors. Mol Ther Nucleic Acids. 2012;1:e30.

16. Callies $\mathrm{S}$, et al. Integrated analysis of preclinical data to support the design of the first in man study of LY2181308, a second generation antisense oligonucleotide. Br JClin Pharmacol. 2011;71(3):416-428.

17. Lindow M, Kauppinen S. Discovering the first microRNA-targeted drug. I Cell Biol. 2012; 199(3):407-412.

18. Chisholm KM, Wan Y, Li R, Montgomery KD, Chang HY, West RB. Detection of long non-coding RNA in archival tissue: correlation with polycomb protein expression in primary and metastatic breast carcinoma. PLoS One. 2012;7(10):e47998.

19. Brunner AL, et al. Transcriptional profiling of IncRNAs and novel transcribed regions across a diverse panel of archived human cancers. Genome Biol. 2012;13(8):R75.
20. Renwick N, et al. Multicolor microRNA FISH effectively differentiates tumor types. J Clin Invest. 2013;123(6):2694-2702

21. Zardo G, et al. Polycombs and microRNA-223 regulate human granulopoiesis by transcriptional control of target gene expression. Blood. 2012;119(17):4034-4046

22. Zardo G, et al. Transcriptional targeting by microRNA-polycomb complexes: a novel route in cell fate determination. Cell Cycle. 2012;11(19):3543-3549.

23. Braun GB, et al. Laser-activated gene silencing via Gold NanoshellsiRNA conjugates. ACS Nano. 2009;3(7):2007-2015

24. Lu W, et al. Tumor site-specific silencing of NF-kappaB p65 by targeted hollow gold nanosphere-mediated photothermal transfection. Cancer Res. 2010;70(8):3177-3188.

25 . Lee SE, et al. Photonic gene circuits by optically addressable siRNA-Au nanoantennas. ACS Nano. 2012;6(9):7770-7780.

26. Ren Y, et al. Targeted tumor-penetrating siRNA nanocomplexes for credentialing the ovarian cancer oncogene ID4. Sci Transl Med.2012;4(147):147ra112.

27. Landon PB, Ramachandran S, Gillman A, Gidron T, Yoon D, Lal R. DNA zipper-based tweezers. Langmuir. 2012;28(1):534-540.

28. Glinsky GV, Berezovska O, Glinskii AB. Microarray analysis identifies a death-from-cancer signature predicting therapy failure in patients with multiple types of cancer.J Clin Invest. 2005;115(6):1503-1521.

\title{
Giardia: both a harmless commensal and a devastating pathogen
}

\author{
Herbert L. DuPont \\ University of Texas School of Public Health and Medical School, St. Luke's Episcopal Hospital, Baylor College of Medicine, \\ and the Kelsey Research Foundation, Houston, Texas, USA
}

\begin{abstract}
The highly prevalent protozoan Giardia lamblia is an enteropathogen that can be asymptomatic in some individuals, while leading to persistent diarrhea and substantial morbidity in others. In this issue of the JCI, Bartelt et al. describe a mouse model of the disease and investigate the contribution of coincident malnutrition with the development of symptomatic infection. This work in part explains how Giardia infection can lead to growth retardation, and may offer insights that guide future therapeutic strategies.
\end{abstract}

Giardia lamblia (synonymous with G. intestinalis and G. duodenalis), referred to herein as Giardia, was first detected in 1681 by Antonie van Leeuwenhoek when looking at his own stools and was later described in 1859 by Lambl (1). Finding the organism as frequently in patients without symptoms as in those with diarrheal illness has led

Conflict of interest: In the past 12 months, the author's university, University of Texas-Houston, has received research grants from Dr. Falk Pharma and INC (Santarus Corporation). The author has received compensation for serving as an expert witness for several lawsuits related to foodborne illness.

Citation for this article: J Clin Invest. 2013 123(6):2352-2354. doi:10.1172/JCI69932. many over the years to conclude that the organism is not a pathogen. Giardia can be identified in stools of $2 \%$ to $5 \%$ of presumably healthy people living in industrialized countries like the United States and in 20\% to $30 \%$ of people in developing regions (2). It is found in water sources and infects many animal species. The organism can be classified into at least 8 different genotypes called assemblages in humans and animals, with assemblages $\mathrm{A}$ and $\mathrm{B}$ being the most important in human infection. Each year in the United States, we identify approximately 20,000 people with Giardia infection, but the actual prevalence is estimated to be much higher.

\section{The two faces of Giardia infection}

In rural areas of the developing world, Giardia is ubiquitous and infects nearly all children, although most remain free of symptoms (3). In these endemic areas, infants experience an acute clinical disease only when first exposed to the protozoan, but quickly recover from infection without adverse long-term effects (4). Self-limiting diarrhea from a Giardia infection is common in young children newly attending day care centers $(5,6)$ and in international travelers (7) to endemic areas when first exposed to the protozoa. After initial exposure in otherwise healthy people, symptomatic infection occurs rarely. Risk factors for first symptomatic infection in young children were shown in one study carried out in rural Egypt to include young age, poverty, low education level, in-home storage of drinking water, and unhygienic treatment of girls related to gender discrimination (8). A proportion of infected people, mainly underweight children with preexistent mal- 


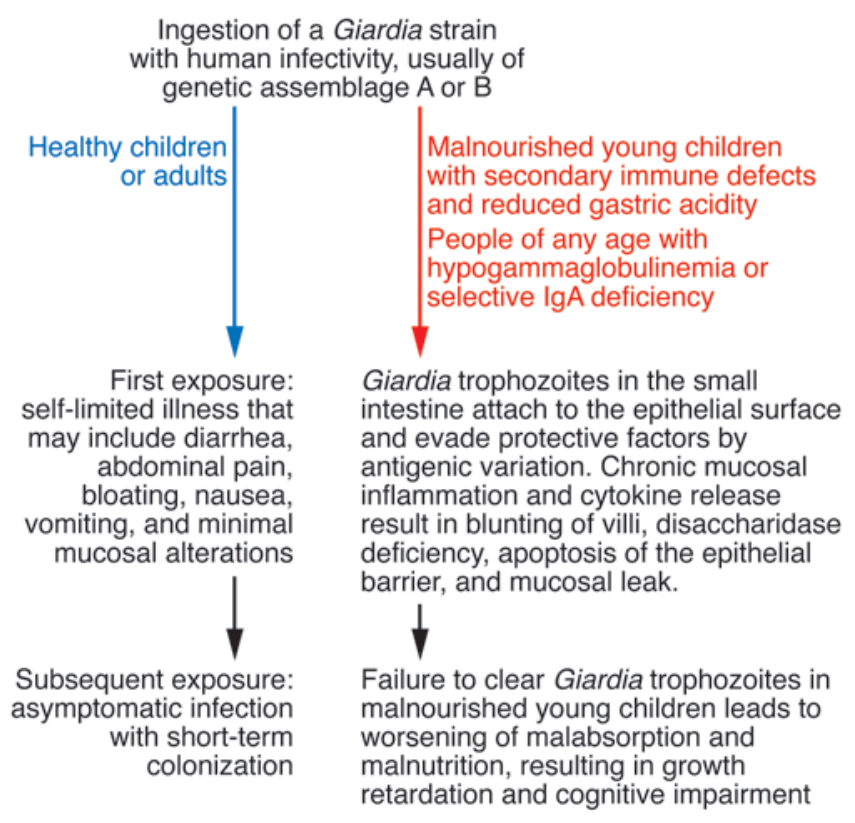

Figure 1

Pathogenesis of Giardia infection.

nutrition, suffer from persistent infection with chronic diarrhea and dramatic health impairments (9), including worsening of nutrition (10), growth retardation, and cognitive impairment (11). In severe cases of giardiasis, during infection Giardia trophozoites attach to the epithelium of the proximal small bowel aided by their ventral adhesive discs, evade host defenses possibly by undergoing genetic variation (12), and produce local alterations of villus structure and cellular apoptosis. The most devastating effects of Giardia infection are related to damage of the absorptive small bowel mucosa, together with abnormal intestinal immunity that favors chronic infection $(13,14)$. While there is little evidence that preexistent malnutrition in young children makes them more susceptible to Giardia infection, once they are infected, persistent symptoms and health consequences are more likely to develop (15). Patients with hypogammaglobulinemia are particularly susceptible to chronic Giardia infection (16). However, Giardia is not a common opportunistic infection in patients with HIV infection or in those with cancer or cancer chemotherapy-induced immunosuppression, suggesting that not all forms of immunosuppression predispose to the infection. The likely explanation for increased symptomatic Giardia infection in infants with first exposure compared with older children and adults is the presence of an immature adaptive immune system in infants (17), particularly in those with preexistent nutritional deficits.

Long-term follow-up studies in children and adults with Giardia infection are needed to understand the relationship between infection and growth and learning defects, persistent abdominal symptoms (18), postinfectious functional bowel disease, and chronic fatigue (19). These chronic illnesses may result from low-level Giardia infections undetected by microscopic examination of stools (10), making their study and identification with previous Giardia infection more difficult.

What determines whether Giardia is a harmless commensal or a devastating pathogen? The difference may relate in part to the virulence of various Giardia strains, and more studies are needed to define these differences between Giardia strains and assemblages, many of which are derived from animal sources (20). In the rural developing world, a majority of young children are surrounded by animals that live in and roam about their homes and that may be sources of Giardia infection (21). A more likely explanation for the two faces of Giardia is the variation in host immune makeup and level of nutrition, although undoubtedly, future studies will reveal that host genetic factors also play an important role. Figure 1 outlines the host and microbial factors that are important in the pathophysiology of asymptomatic and symptomatic giardiasis.

\section{Modeling Giardia infection}

In this issue of the JCI, Bartelt et al. (22) describe a novel animal model of giardiasis in which malnourished, weaned mice developed epithelial apoptosis and crypt hyperplasia associated with a Th2-mediated inflammatory response, persistent shedding of the infecting strain, and growth retardation secondary to Giardia infection. In this model, Giardia infection was associated with vitamin A and zinc deficiency and further impairment in nutrition. Vitamin A and zinc may be particularly relevant because reduced levels of each have been shown to contribute to the persistence of diarrhea. When vitamin $\mathrm{A}$ and zinc are administered with oral rehydration to children with diarrhea, the occurrence of persistent diarrhea is reduced (23).

In the study by Bartelt et al. in this issue of the JCI (22), infection by an assemblage B strain of Giardia led to decreased growth and mucosal histopathological changes similar to those seen in chronic human giardiasis (24). The model allows a characterization of mucosal histopathological response to Giardia infection mimicking that seen in humans, characterized by apoptosis of epithelium with intraepithelial eosinophils, decreased height of villi, alteration of crypt depth and cellularity, and a Th2-based immune response. The model should help us understand the microbial virulence factors and the host factors that work in concert to produce a chronic disease with potentially devastating growth and development parameters, and it suggests that malnutrition is fundamental to the development of host immune changes in chronic intestinal parasitic infection in children in the developing world. Using this new model, we may be able to define the microbe-host interactions of other pathogens including Cryptosporidium and possibly enteroaggregative E. coli known to be associated with growth and development parameters in young children.

\section{Conclusions}

More than 20 previous publications have described mouse or gerbil models of giardiasis, a few studies have developed a model of Giardia infection in rats, and one has been described in zebrafish $(12,25-47)$. These previous animal model studies of giardiasis have documented histopathological alterations associated with infec- 
tion, host immune factors influencing susceptibility, reduced levels of serum zinc, mast cell degranulation, and release of cholecystokinin leading to the alteration of intestinal motility, and the amelioration of experimental infection by probiotics and antimicrobial agents. However, the model developed by Bartelt et al. (22) more closely resembles what is seen in the most severe pediatric Giardia infections in developing regions (20) compared with previous animal studies. The weaned mouse model of malnutrition-related giardiasis, mimicking the situation seen in malnourished infants and young children, should help us better understand real-life events relating to host defenses, Giardia strain virulence, and the role of intestinal immunity and intestinal microbiota in giardiasis. In addition, reversal of the damaging effects of the parasite can be studied in the model by administration of selective immune factors, probiotics, or antiparasitic drugs. There is reason to think that animal models with carefully controlled modifications of the study conditions will help us better understand how this protozoan can be both a harmless commensal and a highly pathogenic organism in vulnerable populations.

\section{Acknowledgments}

The work was supported in part by grants from Public Health Service (DK 56338), which funds the Texas Gulf Coast Digestive Diseases Center.

Address correspondence to: Herbert L. DuPont, 1200 Herman Pressler, Suite 733, Houston, Texas 77030, USA. Phone: 713.500.9366; Fax: 713.500.9359; E-mail: Herbert.L.Dupont@uth.tmc.edu.

1. Faubert G. Immune response to Giardia duodenalis. Clin Microbiol Rev. 2000;13(1):35-54.

2. Ortega YR, Adam RD. Giardia: overview and update. Clin Infect Dis. 1997;25(3):545-549.

3. Sullivan PS, et al. Illness and reservoirs associated with Giardia lamblia infection in rural Egypt: the case against treatment in developing world environments of high endemicity. Am J Epidemiol. 1988; 127(6):1272-1281

4. Hollm-Delgado MG, et al. Lack of an adverse effect of Giardia intestinalis infection on the health of Peruvian children. Am J Epidemiol. 2008;168(6):647-655.

5. Pickering LK, Evans DG, DuPont HL, Vollet JJ 3rd, Evans DJ Jr. Diarrhea caused by Shigella, rotavirus, and Giardia in day-care centers: prospective study. J Pediatr. 1981;99(1):51-56.

6. Pickering LK, Woodward WE, DuPont HL, Sullivan P. Occurrence of Giardia lamblia in children in day care centers. J Pediatr. 1984;104(4):522-526.

7. Gautret P, et al. Infectious diseases among travellers and migrants in Europe, EuroTravNet 2010. Euro Surveill. 2012;17(26):pi=20205.

8. Mahmud MA, Chappell C, Hossain MM, Habib M, Dupont HL. Risk factors for development of first symptomatic Giardia infection among infants of a birth cohort in rural Egypt. Am J Trop Med Hyg. 1995;53(1):84-88.

9. Muhsen K, Levine MM. A systematic review and meta-analysis of the association between Giardia lamblia and endemic pediatric diarrhea in developing countries. Clin Infect Dis. 2012;55(suppl 4):S271-S293.

10. Ignatius R, et al. High prevalence of Giardia duodenalis Assemblage B infection and association with underweight in Rwandan children. PLoS Negl Trop Dis. 2012;6(6):e1677.

11. Ajjampur SS, et al. Effect of cryptosporidial and giardial diarrhoea on social maturity, intelligence and physical growth in children in a semi-urban slum in south India. Ann Trop Paediatr. 2011;31(3):205-212.

12. Prucca CG, Rivero FD, Lujan HD. Regulation of antigenic variation in Giardia lamblia. Annu Rev Microbiol. 2011;65:611-630.

13. Hanevik K, et al. Human cellular immune response against Giardia lamblia 5 years after acute giardiasis. J Infect Dis. 2011;204(11):1779-1786.

14. Long KZ, et al. Associations between mucosal innate and adaptive immune responses and resolution of diarrheal pathogen infections. Infect Immun. 2010;78(3):1221-1228.

15. Sullivan PB, et al. Prevalence and treatment of giardiasis in chronic diarrhoea and malnutrition. Arch Dis Child. 1991;66(3):304-306.

16. Ghoshal UC, Goel A, Ghoshal U, Jain M, Misra A, Choudhuri G. Chronic diarrhea and malabsorption due to hypogammaglobulinemia: a report on twelve patients. Indian J Gastroenterol. 2011;30(4):170-174.

17. Eckmann L, Gillin FD. Microbes and microbial toxins: paradigms for microbial-mucosal interactions I. Pathophysiological aspects of enteric infections with the lumen-dwelling protozoan pathogen Giardia lamblia. Am J Physiol Gastrointest Liver Physiol. 2001;280(1):G1-G6.

18. Morch K, et al. Severity of Giardia infection associated with post-infectious fatigue and abdominal symptoms two years after. BMC Infect Dis. 2009;9:206.

19. Wensaas KA, Langeland N, Hanevik K, Mørch K, Eide GE, Rortveit G. Irritable bowel syndrome and chronic fatigue 3 years after acute giardiasis: historic cohort study. Gut. 2012;61(2):214-219.

20. Cotton JA, Beatty JK, Buret AG. Host parasite interactions and pathophysiology in Giardia infections. Int J Parasitol. 2011;41(9):925-933.

21. Wright CE, et al. The role of home environment in infant diarrhea in rural Egypt. Am J Epidemiol. 1991;134(8):887-894.

22. Bartelt LA, et al. Persistent G. lamblia impairs growth in a murine malnutrition model. J Clin Invest. 2013;123(6):2672-2684

23. Rahman MM, Vermund SH, Wahed MA, Fuchs GJ, Baqui AH, Alvarez JO. Simultaneous zinc and vitamin A supplementation in Bangladeshi children: randomised double blind controlled trial. $B M J$. 2001;323(7308):314-318.

24. Troeger H, et al. Effect of chronic Giardia lamblia infection on epithelial transport and barrier function in human duodenum. Gut. 2007;56(3):328-335.

25. Araújo NS, et al. Giardia duodenalis: pathological alterations in gerbils, Meriones unguiculatus, infected with different dosages of trophozoites. Exp Parasitol. 2008;118(4):449-457.

26. Astiazarán-García H, Espinosa-Cantellano M, Castañón G, Chávez-Munguía B, Martínez-Palomo A. Giardia lamblia: effect of infection with symptomatic and asymptomatic isolates on the growth of gerbils (Meriones unguiculatus). Exp Parasitol. 2000;95(2):128-135.

27. Bénéré E, Van Assche T, Cos P, Maes L. Variation in growth and drug susceptibility among Giardia duodenalis assemblages $\mathrm{A}, \mathrm{B}$ and $\mathrm{E}$ in axenic in vitro culture and in the gerbil model. Parasitology. 2011;138(11):1354-1361.
28. Bénéré E, Van Assche T, Van Ginneken C, Peulen $\mathrm{O}$, Cos P, Maes L. Intestinal growth and pathology of Giardia duodenalis assemblage subtype A(I), $\mathrm{A}(\mathrm{II}), \mathrm{B}$ and $\mathrm{E}$ in the gerbil model. Parasitology. 2012; 139(4):424-433.

29. Benyacoub J, et al. Enterococcus faecium SF68 enhances the immune response to Giardia intestinalis in mice. J Nutr. 2005;135(5):1171-1176.

30. Bouza M, Maciques I, Torres D, Núñez FA. Giardia lamblia in Mongolian gerbils: characteristics of infection using different human isolates. Exp Parasitol. 2000;96(1):43-46.

31. Cevallos A, Carnaby S, James M, Farthing JG. Small intestinal injury in a neonatal rat model of giardiasis is strain dependent. Gastroenterology. 1995; 109(3):766-773.

32. El-Taweel HA, El-Zawawy LA, Said DE, Sharara GM. Influence of the antioxidant drug (Antox) on experimental giardiasis and microsporidiosis. J Egypt Soc Parasitol. 2007;37(1):189-204.

33. Hardin JA, Buret AG, Olson ME, Kimm MH, Gall DG. Mast cell hyperplasia and increased macromolecular uptake in an animal model of giardiasis. J Parasitol. 1997;83(5):908-912.

34. Hassan SI, Nessim NG, Mahmoud SS, Nosseir MM. Effect of a broad spectrum antiparasitic drug "ivermectin" in acute and chronic experimental giardiasis using different dose regimens. J Egypt Soc Parasitol. 2001;31(2):419-428.

35. Langford TD, et al. Central importance of immunoglobulin A in host defense against Giardia spp. Infect Immun. 2002;70(1):11-18.

36. Lemee V, et al. Metronidazole and albendazole susceptibility of 11 clinical isolates of Giardia duodenalis from France. J Antimicrob Chemother. 2000; 46(5):819-821.

37. Li E, Zhao A, Shea-Donohue T, Singer SM. Mast cell-mediated changes in smooth muscle contractility during mouse giardiasis. Infect Immun. 2007;75(9):4514-4518.

38. Lu S, Luo X, Chen X, Wang F. Establishment of a $\mathrm{C} 57 \mathrm{BL} / 6 \mathrm{~N}$ mouse model of giardiasis. Chin Med J (Engl). 2002;115(10):1453-1456.

39. Mohanty MC, Ravindran B. Deficiency of antibody responses to $\mathrm{T}$-independent antigens in gerbils - Meriones unguiculatus. Dev Comp Immunol. 2002;26(4):385-391.

40. Quihui-Cota L, et al. Changes in serum zinc levels associated with giardiasis and dietary zinc intake in mice. Biol Trace Elem Res. 2012;145(3):396-402.

41. Shukla G, Sidhu RK. Lactobacillus casei as a probiotic in malnourished Giardia lamblia-infected mice: a biochemical and histopathological study. Can J Microbiol. 2011;57(2):127-135.

42. Solaymani-Mohammadi S, Singer SM. Host immunity and pathogen strain contribute to intestinal disaccharidase impairment following gut infection. J Immunol. 2011;187(7):3769-3775.

43. Tysnes KR, Jørgensen A, Poppe T, Midtlyng PJ, Robertson LJ. Preliminary experiments on use of zebrafish as a laboratory model for Giardia duodenalis infection. Acta Parasitol. 2012;57(1):1-6.

44. Velazquez C, et al. Giardia lamblia infection induces different secretory and systemic antibody responses in mice. Parasite Immunol. 2005;27(9):351-356.

45. Ventura LL, Oliveira DR, Viana JC, Santos JF, Caliari MV, Gomes MA. Impact of protein malnutrition on histological parameters of experimentally infected animals with Giardia lamblia. Exp Parasitol. 2013;133(4):391-395.

46. von Allmen N, Christen S, Forster U, Gottstein B, Welle M, Müller N. Acute trichinellosis increases susceptibility to Giardia lamblia infection in the mouse model. Parasitology. 2006;133(pt 2):139-149.

47. Zhou P, Li E, Shea-Donohue T, Singer SM. Tumour necrosis factor alpha contributes to protection against Giardia lamblia infection in mice. Parasite Immunol. 2007;29(7):367-374. 